\title{
Do Adjustment Costs Explain Investment-Cash Flow Insensitivity?*
}

\author{
Sangeeta Pratap \\ Centro de Investigación Económia, \\ Instituto Tecnológico Autónomo de México (ITAM) \\ July 1999
}

\begin{abstract}
In this paper, I explain two "puzzles" which have been observed in firm level data.

(1) Firms which display a high sensitivity of investment to cash flow (commonly believed to be an indicator of liquidity constraints) usually have large unutilized lines of credit which, presumably, could be used to overcome the shortage of funds

(2) Firms which are perceived to be extremely liquidity constrained actually show very little sensitivity of investment to cash flow.

I use a dynamic model of firm investment with liquidity constraints and non convex costs of adjustment of capital which can explain these facts. The fixed cost of adjustment implies that firms need to have a certain threshold level of financial resources before they can afford to invest and incur these costs. Below this level, investment will not be sensitive to increases in cash flow. Once they cross this threshold, firms' investment will be positively correlated with their financial resources until they reach their desired level of capital stock. However, even if investment is sensitive to cash flow, firms always borrow below their credit limit to guard against future bankruptcy or binding liquidity constraints.

I show therefore, that a firm which displays investment cash-flow sensitivity is certainly liquidity constrained. However, the reverse is not necessarily true.
\end{abstract}

\footnotetext{
*I am grateful to Mark Gertler, Steve Bond, Costas Meghir, Silvio Rendón and participants at the 1999 SED Meetings for very helpful suggestions. The responsibility for all errors is mine. Address: Centro de Investigación Económia, ITAM, Av. Camino de Sta. Teresa \# 930, Mexico D.F. 10700. Email: pratap@master.ster.itam.mx
} 


\section{Introduction}

In this paper, I provide an explanation for two apparently counter-intuitive empirical regularities: (1) Firms which primarily rely on internal funds to increase investment usually have access to external funds which they do not use; and (2) Firms which appear to be severely liquidity constrained and without any discernable sources of external finance display very little correlation between their internal resources and investment (Kaplan and Zingales 1997).

The above evidence has been used by Kaplan and Zingales (henceforth KZ) to argue against a large body of literature on investment which says that additional explanatory power provided by cash flow in a regression of investment against Tobin's $q$ is an indicator of liquidity constraints. For example, Fazzari, Hubbard and Peterson (1988) (henceforth FHP) found that the sensitivity of investment to cash flow was much higher for firms which were a priori expected to be liquidity constrained according to some other criteria. In a sample of 422 U.S. firms from the Value Line database, a sub-sample of 49 firms with dividend income ratios less than 0.1 displays a much higher correlation between investment and cash flow than the remaining firms with higher dividend to income ratios. This finding has been replicated for several data sets and sample splits. ${ }^{1}$

\footnotetext{
${ }^{1}$ Hoshi, Kashyap \& Scharfstein (1991) find that membership of an industrial keiretsu in Japan reduces the sensitivity of investment to cash flow. Similar results are obtained when the sample is divided on the basis of bond ratings (Gilchrist \& Himmelberg 1995) and size (Gertler \& Gilchrist 1994). Firm level data for the U.K. (Devereaux and Schiantarelli 1989), Italy (Schiantarelli \& Sembellini 1995) and Canada (Schaller 1993) have all confirmed that constrained firms display a higher sensitivity of investment to cash flow. For a detailed review of this literature, see Hubbard
} 
KZ demonstrate that if the sub-sample of 49 firms is further divided into constrained and unconstrained firms, the investment expenditure of the former category is less sensitive to cash flow than that of the latter category. This sub-division is done on the basis of a detailed examination of the firms' annual reports, letters to shareholders, statements by the management, entries in The Wall Street Journal Index etc. Firms which document difficulties in obtaining external funds, or have been forced to cut dividends or are renegotiating debt repayments are classified as constrained. On the other hand, firms with low debt, unused lines of credit, large amounts of internal funds and collateralizable resources are considered unconstrained.

In what follows, I shall argue that from a theoretical point of view, a high sensitivity of investment to cash flow is an indicator of liquidity constraints. However, the reverse is not necessarily true, i.e. liquidity constraints do not necessarily imply sensitivity of investment to cash flow. In other words, KZ's identification of firms with unused credit lines and high investment-cash flow sensitivities as unconstrained is erroneous. However, as they document, it is not necessary for investment and cash flow of constrained firms to be correlated.

I use a dynamic model of firm investment with liquidity constraints and non convex costs of adjustment of capital which explains the KZ results. I show that for some firms, the existence of unutilized lines of credit is compatible with the presence of liquidity constraints. Such firms display a high sensitivity of investment to cash flow. (1998). 
The presence of fixed costs of adjustment of capital, on the other hand, implies that investment does not increase with cash flow for some firms, since the increase in cash flow may not be adequate to cover the fixed cost of changing the capital stock. Cash flow has to be above a certain threshold level for these firms to display a positive relationship between investment and cash flow.

I conclude therefore, that disregarding issues involved in the measurement of $q$, the FHP methodology, based on the sensitivity of investment to cash flow, provides a useful way to distinguish between constrained and unconstrained firms. However, within the group of liquidity constrained firms, some firms may display lower investment-cash flow sensitivities, depending on other factors such as adjustment costs technologies.

The paper is organized as follows. The next section sets out the model. Section 3 provides the solution to the model and derives the results mentioned above. In Section 4, I simulate a data set and split it according to both the FHP and KZ criteria. Running the investment equations on the various sub-samples gives us the KZ results as well as the FHP results, showing that the model is capable of explaining both these apparently contradictory facts. Section 5 concludes. 


\section{The Model}

I use a dynamic model of firm investment with liquidity constraints and adjustment costs which is based on Gross (1994). The model ${ }^{2}$ combines two strands of the recent literature which seeks to explain the relatively low response of investment to fundamentals. One strand argues that liquidity constraints arising from asymmetric information and other imperfections in capital markets may imply that financial factors may be an important determinant of firm investment. ${ }^{3}$ The other line of reasoning highlights irreversibilities and fixed costs of adjustment of capital to explain why investment tends to be episodic and unresponsive to fundamentals. (See for example Abel and Eberly (1994), Caballero and Leahy (1996), Bertola and Caballero (1994), Caballero (1997).)

The firm chooses investment and borrowing to maximize its stream of discounted future income i.e.

$$
\max _{\left\{I_{t}, B_{t+1}\right\}_{t=0}^{\infty}} E_{0}\left(\sum_{t=0}^{\infty} \beta^{t} D_{t}\right)
$$

where $D_{t}=$ dividends at time $t$, and are defined as

$$
D_{t}=\theta_{t} K_{t}^{\alpha}-I_{t}-C\left(I_{t}, K_{t}\right)+B_{t+1}-(1+r) B_{t}
$$

\footnotetext{
${ }^{2}$ A version of this model was estimated in Pratap and Rendón (1998) and used to quantify the effect of liquidity constraints on firm investment.

${ }^{3}$ See Hubbard (1998) for a review of the theoretical and empirical literature and the references therein.
} 
$B_{t}$ is the firm's debt at time $t$ and $r$ is the interest rate which is paid on it. All debt contracts are assumed to be one period. $I_{t}$ is the firm's investment and $C\left(I_{t}, K_{t}\right)$ is the cost of adjustment of capital.

$K_{t+1}$ is the capital stock at time $t+1$ and has the following law of motion

$$
K_{t+1}=(1-\delta) K_{t}+I_{t}
$$

$\theta_{t}$ is a firm specific technology shock. with a distribution $F$ and is defined over the range $[\underline{\theta}, \bar{\theta}] \delta$ is the depreciation rate which is assumed to be the same for all firms and constant over time.

\subsection{Adjustment Costs}

In deriving the investment equation, the neo-classical theory of investment has traditionally treated investment as reversible, with smooth costs of adjustment (Hayashi 1982). However, several studies have documented the importance of lumpy investment for manufacturing plants (see for example, Caballero, Engels \& Haltiwanger 1995). Doms \& Dunne (1994) find that investment spikes account for a large fraction

of plant investment. Cooper, Haltiwanger \& Power (1995) find that the probability of a spike occuring increases with the time elapsed since the previous spike. Barnett \& Sakellaris (1998) and Abel \& Eberly (1995) find that observed investment patterns at the firm level are not compatible with those implied by smooth costs of adjustment. Goolsbee \& Gross (1997) use disaggregated data for heterogeneous capital stock in 
the airline industry and find evidence of significant non convexities.

I assume fixed (scale dependent) costs of adjustment of capital i.e.

$$
\begin{aligned}
C\left(I_{t}, K_{t}\right) & =c K_{t} \text { if } I_{t} \neq 0 \\
& =0 \quad \text { if } I_{t}=0
\end{aligned}
$$

To contrast my results with the case of smooth adjustment costs, I also consider the standard quadratic cost of adjustment case.

$$
\begin{aligned}
C\left(I_{t}, K_{t}\right) & =c\left(\frac{I_{t}}{K_{t}}\right)^{2} & & \text { if } I_{t} \neq 0 \\
& =0 & & \text { if } I_{t}=0
\end{aligned}
$$

In what follows, I shall study the implications of each of these types of costs for the sensitivity of investment to financial resources for various types of firms.

\section{$2.2 \quad$ Financial Constraints}

I also assume two types of financial constraints which are imposed on the firm. First the firm is not allowed to issue fresh equity, ${ }^{4}$ i.e. dividends are always constrainted

\footnotetext{
${ }^{4}$ External finance is typically more expensive than internal finance. Asymmetric information between investors and managers leads the former to demand an equity premium (Myers and Majluf 1984, Greenwald, Stiglitz and Weiss 1984).
} 
to be non negative

$$
D_{t} \geq 0 \quad \forall t
$$

This implies that internal funds are the main source of funds for investment, augmented to a limited extent by debt.

Financial resources $x_{t}$ are defined as the sum of profits and undepreciated capital less debt repayments in the current period, i.e.

$$
x_{t}=\theta_{t} K_{t}^{\alpha}+(1-\delta) K_{t}-(1+r) B_{t}
$$

To prevent firms from borrowing more than an amount they can repay in the next period, the borrowing limit is related to the firms financial condition. A firm can only borrow up to the point which ensures that it can repay its debt with certainty in the next period. ${ }^{5} B_{t+1}$ must therefore satisfy the following condition:

$$
\operatorname{Min}\left(x_{t+1} \mid x_{t}\right)>0
$$

or

$$
\left(\underline{\theta} K_{t+1}^{\alpha}+(1-\delta) K_{t+1}-(1+r) B_{t+1} \mid x_{t}\right)>0
$$

The structure of information and decision making in the model is as follows: Firms

\footnotetext{
${ }^{5}$ We have chosen the tightest possible borrowing constraint, to show that firms will still have unused lines of credit.
} 
enter any period $t$ with a given capital stock $\left(K_{t}\right)$ and debt $\left(B_{t}\right)$. They observe the value of the shock at time $t$, which determines their financial resources $x_{t}$. Given this value of $x_{t}$ and the constraints they face, the firms choose their capital stock $K_{t+1}$, and debt $B_{t+1}$, for the next period.

The value function can be written as

$$
\begin{aligned}
V\left(K_{t}, B_{t}, \theta_{t}\right)= & \max _{I_{t}, B_{t+1}} \theta_{t} K_{t}^{\alpha}-(1+r) B_{t}-C\left(I_{t}, K_{t}\right) \\
& -I_{t}+B_{t+1}+\beta E V\left(K_{t+1}, B_{t+1}, \theta_{t+1}\right)
\end{aligned}
$$

subject to the constraints (5) and (7). If the shock is serially uncorrelated, this can be alternatively written in terms of $x_{t}$ as

$$
V\left(x_{t}, K_{t}\right)=\max _{K_{t+1}, B_{t+1}} x_{t}-K_{t+1}-C\left(K_{t+1}, K_{t}\right)+B_{t+1}+\beta E\left(V\left(x_{t+1}, K_{t+1}\right)\right)
$$

subject to the above constraints. $K_{t}$ appears as an additional state variable because of the presence of adjustment costs.

\section{Solution of the Model}

Since this model cannot be solved analytically, we compute a numerical solution for assigned parameter values by discretizing the state space and finding the fixed point of the value function. The probability distribution of $\theta$ is parameterized as a normal 
distribution with mean $\mu$ and standard deviation $\sigma,^{6}$

\subsection{Fixed Costs of Adjustment}

Iterating on the value function (9) yields the policy rules as functions of the state space

$$
\begin{aligned}
& K_{t+1}=K\left(K_{t}, B_{t}, \theta_{t}\right) \\
& B_{t+1}=B\left(K_{t}, B_{t}, \theta_{t}\right)
\end{aligned}
$$

or alternatively

$$
\begin{gathered}
K_{t+1}=K\left(x_{t}, K_{t}\right) \\
B_{t+1}=B\left(x_{t}, K_{t}\right)
\end{gathered}
$$

The parameter values used in this simulation are given below:

\begin{tabular}{llll}
\hline \hline$\alpha=0.6$ & $r=$ & 0.02 \\
$\beta=$ & 0.98 & $\mu=$ & 2.5 \\
$\delta=$ & 0.12 & $\sigma=$ & 1.5 \\
$c=$ & 0.011 & \\
\hline \hline
\end{tabular}

The value of $\beta$ used is consistent with a discount rate of 2 percent. All other parameters except the cost of adjustment are based on the parameters estimated in

\footnotetext{
${ }^{6}$ Since the probability distribution is discretized, the bounds $[\underline{\theta}, \bar{\theta}]$ are taken as $[\mu-3 \sigma, \mu+3 \sigma]$. Similar results obtain for log normal distributions with a lower bound of zero.
} 
Pratap \& Rendón (1998). Since lenders do not bear any risk in lending to the firm, the rate of interest is the same as the discount rate. The cost of adjustment parameter is based on Abel \& Eberly (1996) who estimate that costs of adjustment are roughly equal to $1.1 \%$ of investment in the manufacturing sector. ${ }^{7}$

Figure 1 shows the policy rules as a function of the state $x_{t}$, for given levels of $K_{t}$. Three patterns of capital accumulation can be observed, depending on the level of $x_{t}$. When $x_{t}<x^{*}$, firm investment is completely unresponsive to increases in financial resources. The firm does not have internal funds to cover the fixed cost of adjustment and is prevented from borrowing the necessary amount. In the intermediate range, firms with $x^{*}<x_{t}<x^{* *}$, which are below their desired level of capital are able to increase investment as their financial resources improve. Finally, firms with $x_{t}>x^{* *}$ have already reached their desired level of capital and do not respond to further increases in $x_{t} \cdot{ }^{8}$ This figure also shows us a natural way to identify liquidity constrained firms that is implied by the model, i.e firms which have not reached their desired level of capital stock are classified as liquidity constrained.

The same figure also shows us debt as a function of $x_{t}$. Firms with financial resources below $x^{*}$ do not incur any debt. For firms with $x_{t}>x^{*}$, debt is an inverted U shaped function of financial resources. If firms did not face a borrowing constraint,

\footnotetext{
${ }^{7}$ Choosing an appropriate adjustment cost parameter is difficult, since most available estimates are based on smooth adjustment costs and are implausibly high (Chirinko 1993). For example, the lowest estimate Schaller (1981) gets is 28.6 after allowing for heterogeneity as well as imperfect competition. Goolsbee \& Gross (1997) use non parametric methods to show that if they aggregate capital to the firm level, their estimates get biased upwards and evidence of non convexities disappear.

${ }^{8}$ This policy rule is shown for a given value of $K_{t}$. Higher values of $K_{t}$ leave the shape of the policy function unchanged but shift $x^{*}$ to the right.
} 
this function would be monotonically declining, since poorer firms would need to borrow more than rich firms to reach their desired level of capital. However, since the amount a firm can borrow is limited by its financial position, increases in $x_{t}$ allow a firm to borrow more and increase its capital stock. If the borrowing constraint is relaxed, firms are able to borrow enough to instantaneously reach their desired level of capital, regardless of the value of current financial resources. Debt is a decreasing function of $x_{t}$.

Figure 2 shows firms debt as compared to their credit ceiling. The interesting feature here is the existence of unused credit lines even for firms whose investment is sensitive to cash flow. This is because in addition to the borrowing constraint, the firm also faces a non negativity constraint on its dividends. Higher borrowing today would result in lower $x$ tomorrow and the firm would have to borrow more in the next period so that it does not violate the dividend constraint. This amount of borrowing could violate the borrowing constraint tomorrow.

Kaplan and Zingales argue that these firms cannot be considered liquidity constrained since they are in a position to increase investment if they choose, as evidenced by their unused credit lines. However, these firms are definitely constrained in a dynamic sense since considerations of future constraints affect their borrowing in the current period.

In the context of the model, liquidity constrained firms have been defined as firms whose capital stock is below the desired level of capital. Figure 3 shows the slope 
of the value function with respect to $x_{t}$, i.e. the shadow value of internal financial resources. This value is greater than 1 for all firms with $x_{t}<x^{* *}$, which includes both firms whose investment is unresponsive to increases in cash flow (i.e. firms with $x_{t}<x^{*}$ ) and firms which display sensitivity of investment to cash flow (i.e. $\left.x^{*}<x_{t}<x^{* *}\right)$.

Therefore we see that this simple model is able to reconcile two counter intuitive empirical regularities observed in the data. (1) Firms which display a high degree of sensitivity of investment to cash flow can simultaneously have unused lines of credit and (2) Firms which are the most severely liquidity constrained do not respond to increases in their financial position by increasing their investment. The features of the model which are crucial in obtaining these results are (1) the dynamic nature of the model which requires the firm to take into account not only current but also anticipated liquidity and borrowing constraints and (2) the interaction between liquidity constraints and fixed costs of adjustment of capital.

\subsection{Convex Costs of Adjustment}

To contrast my findings with the conventional smooth adjustment costs, I also present simulations of the model with convex adjustment costs $(4)^{9}$ The policy rules can now be written as:

\footnotetext{
${ }^{9}$ The parameters are the same as used in the previous simulation.
} 


$$
\begin{aligned}
& K_{t+1}=K\left(x_{t}, K_{t}\right) \\
& B_{t+1}=B\left(x_{t}, K_{t}\right)
\end{aligned}
$$

Figure 4 shows the optimal capital stock as a function of $x_{t}$ for different values of $K_{t}{ }^{10}$ Since the costs of adjustment are incremental in nature, there is no region of unresponsiveness to increases in $x_{t}$ for liquidity constrained firms. The policy function shifts upwards for higher values of $K_{t}$ since adjusting capital becomes cheaper as $K_{t}$ increases.

Figure 5 shows the policy rule for $B_{t+1}$ as a function of $x_{t}$ for different values of $K_{t}$. The policy rule is still maintains the same inverted $\mathrm{U}$ shape and shifts upwards for higher values of $K_{t}$.

\section{Reduced Form Investment Equations}

In this section I simulate a panel of 500 firms for 20 years to estimate cross sectional investment equations. The purpose of this exercise is to see whether data generated by the model can be split in a manner as to replicate the FHP and KZ results simultaneously.

\footnotetext{
${ }^{10} x_{t}$ can only take a limited set of values, depending on the values of $K_{t}, B_{t}$, and $\theta_{t}$. For low values of $K_{t}$ the set of positive $x_{t}$ is obviously much smaller than for higher values of $K_{t}$. Therefore $K_{t+1}$ and $B_{t+1}$ are defined over a smaller set of $x$ for low $K_{t}$.
} 
Table 1: Summary Statistics for the FHP Classification

\begin{tabular}{lccc|ccc}
\hline \hline & \multicolumn{3}{c|}{ Group 1 } & \multicolumn{3}{c}{ Group 2 } \\
& Max. & Min. & Average & Max. & Min & Average \\
\hline$I_{t} / K_{t}$ & 3.453 & -0.880 & 0.088 & 0.120 & -0.672 & 0.005 \\
$x_{t} / K_{t}$ & 2.587 & 0.002 & 0.685 & 1.266 & 0.385 & 0.774 \\
Tobin's $q$ & 73.385 & 0.000 & 6.268 & 2.982 & 0.621 & 1.077 \\
$B_{t+1} / K_{t}$ & 2.473 & 0.000 & 0.341 & 0.002 & 0.000 & 0.001 \\
Slack $/ K_{t}$ & 0.669 & 0.000 & 0.242 & 0.791 & 0.139 & 0.265 \\
Dividends $/ K_{t}$ & 0.797 & 0.000 & 0.046 & 1.024 & 0.070 & 0.401 \\
\hline \hline
\end{tabular}

Note: Group 1 firms have $x_{t}<x^{* *}$ for more than $80 \%$ of the sample period. Group 2 comsists of firms with $x_{t} \geq x^{* *}$ for at least $80 \%$ of the sample period.

The first sample split, in the spirit of FHP, is between firms whose internal financial resources $x_{t}$ are less than $x^{* *}$ for more than $80 \%$ of the sample period (Group 1 ), and those for which $x_{t} \geq x^{* *}$ for more than $80 \%$ of the sample period (Group 2). Summary statistics for each of these subgroups of firms are presented in Table 1.

As the table shows, Group 1 firms invest more, pay lower dividends and have a higher $q$ than Group 2 firms. ${ }^{11}$ They also hold more debt and are closer to their credit limit. ${ }^{12}$ This sub-division of firms therefore, captures several features of the FHP classification.

Investment equations for both these groups are presented in Table 2. The model predicts that Group 1, which includes the liquidity constrained firms, should show a strong relationship between investment and $x_{t}$. On the other hand, Group 2 firms have, by and large, reached their desired level of capital and should therefore not

\footnotetext{
${ }^{11}$ We use marginal $q$ here which is defined as the numerical derivative $\frac{d E V\left(x_{t+1}, K_{t+1}\right)}{d K_{t+1}}$.

${ }^{12}$ Slack is defined as the difference between the credit ceiling and actual borrowing.
} 
Table 2: FHP Regressions

\begin{tabular}{|l|rr|rr|}
\hline \multicolumn{4}{|c|}{ Dependent Variable $=\frac{I_{t}}{K_{t}}$} \\
\hline & \multicolumn{2}{|c|}{ Group 1 } & \multicolumn{2}{c|}{ Group 2 } \\
& Coeff. & Std. Error & Coeff & Std. Error \\
\hline Constant & -0.5463 & 0.0108 & -0.8800 & 0.0000 \\
$x_{t} / K_{t}$ & 0.9327 & 0.0178 & 0.0000 & 0.0000 \\
$q_{t}$ & -0.0007 & 0.0006 & 0.3354 & 0.0000 \\
\hline
\end{tabular}

show any relationship between $x_{t}$ and investment.

The coefficient on the financial variable $x_{t}$ is almost 1 for Group 1 firms. ${ }^{13}$. Since $x$ and $q$ are very closely related to each other here, the coefficient on $q$ is almost zero and not significant. Group 2 firms, conversely have a zero coefficient on $x$, while the coefficient on $q$ is higher and very significant. ${ }^{14}$

Group 1 firms are further subdivided into two groups to capture the KZ firm classification. This classification is based on the amount of external finance available. Firms which borrow upto their credit limit for at least $80 \%$ of the sample period are included in Group 1a (the counterpart of the liquidity constrained firms in the KZ scheme) whereas firms with some available credit comprise Group 1b. Table 3 shows summary statistics for these firms.

Group 1a firms have several features which are very similar to the firms identified

\footnotetext{
${ }^{13}$ If we exclude firms with $x_{t}<x^{*}$ the coefficient is greater than 1 because increases in $x$ also allow the firm to borrow.

${ }^{14}$ FHP get a positive coefficient on cash flow for the latter group as well. However since their measure of $q$ contains some measurement error, the cash flow variable captures some of the investment opportunites which are not contained in $q$.
} 
Table 3: Summary Statistics for the KZ Classification

\begin{tabular}{lccc|ccc}
\hline \hline & \multicolumn{3}{c|}{ Group 1a } & \multicolumn{3}{c}{ Group 1b } \\
& Max. & Min. & Average & Max. & Min & Average \\
\hline$I_{t} / K_{t}$ & 2.120 & -0.880 & 0.004 & 3.453 & -0.860 & 0.136 \\
$x_{t} / K_{t}$ & 2.126 & 0.002 & 0.640 & 2.589 & 0.050 & 0.689 \\
Tobin's $q$ & 73.385 & 0.000 & 25.131 & 73.385 & 0.879 & 4.524 \\
$B_{t+1} / K_{t}$ & 0.968 & 0.000 & 0.120 & 2.473 & 0.000 & 0.361 \\
Slack/ $K_{t}$ & 0.323 & 0.000 & 0.090 & 0.791 & 0.000 & 0.281 \\
Dividends $/ K_{t}$ & 0.543 & 0.000 & 0.022 & 0.797 & 0.000 & 0.303 \\
\hline \hline
\end{tabular}

Note: Group 1a firms are firms with zero unutilized credit and $x_{t} \leq x^{* *}$ for at least $80 \%$ of the sample period. Group $1 \mathrm{~b}$ firms have at least some unutilized credit for more than $80^{\prime}$

Table 4: KZ Regressions

\begin{tabular}{|l|rr|rr|}
\hline \multicolumn{4}{|c|}{ Dependent Variable $=\frac{I_{t}}{K_{t}}$} \\
\hline & \multicolumn{2}{|c|}{ Group 1a } & \multicolumn{2}{c|}{ Group 1b } \\
& Coeff. & Std. Error & Coeff & Std. Error \\
\hline Constant & -0.9268 & 0.0151 & -0.4256 & 0.0109 \\
$x_{t} / K_{t}$ & 0.2320 & 0.0713 & 0.6810 & 0.0164 \\
$q_{t}$ & 0.0137 & 0.0009 & 0.0205 & 0.0010 \\
\hline
\end{tabular}

as liquidity constrained by KZ. They tend to have lower investment and lower slack than Group 1b firms. Since they have access to fewer external resources, they are unable to borrow as much. They also have a lower level of financial resources, and pay less dividends than Group $1 \mathrm{~b}$ firms.

The corresponding investment equations for both these groups are presented in Table 4. 
The coefficient on $x_{t}$ for Group 1a firms is 0.23 . This is well within the range of the corresponding $\mathrm{KZ}$ estimates which vary from 0.14 to 0.3 , depending on the specification of the equation. The coefficient for the other group is much higher at 0.68. The KZ estimates for this group lie between 0.43 and 0.801 .

Thus we see that the model is extremely successful in replicating both the FHP and the $\mathrm{KZ}$ results. Investment and cash flow are strongly related for firms with $x_{t}<x^{* *}$. For firms with $x_{t} \geq x^{* *}$ this correlation is zero. Subdividing the former group on the basis of the availability of external funds reveals that firms with significant amounts of available credit display a strong sensitivity of investment to cash flow. On the other hand this relationship is not observed for firms with very low availability of external funds.

\section{Conclusions}

I present a simple dynamic model with liquidity constraints and non convex costs of adjustment of capital based on Gross (1994). Both these features have been separately emphasized in the theoretical and empirical literature as important determinants of investment. Combining financial and real frictions explains two puzzles in the firm investment literature (1) Firms which are extremely liquidity constrained do not change their investment in response to incremental changes in cash flow and (2) Several firms rely on internal funds to increase investment despite the availability of external sources of finance. 
I show that while the sensitivity of investment to cash flow implies that a firm is liquidity constrained, the reverse may not necessarily be true. Liquidity constrained firms prefer to use internal funds for investment and borrow below their credit limit to guard against violating future constraints, and may thus display a high sensitivity of investment to cash flow and unused lines of credit simultaneously.

Similarly, the presence of fixed costs of adjustment imply that for some firms, increases in cash flow are not adequate to cover investment expenditure as well as the fixed cost of changing the capital stock. Investment responds to increases in cash flow only when a firm is wealthy enough to afford both these components of investment.

Therefore, investment-cash flow sensitivities still provide a useful way to distinguish between liquidity constrained and unconstrained firms. However, investment may be relatively insensitive to cash flow for a certain subset of constrained firms due to non convexities in the adjustment cost technology. 


\section{References}

[1] Abel, A. B. \& Eberly, J. (1994), 'A Unified Model of Investment Under Uncertainty', American Economic Review 84, 1369-1384.

[2] Abel, A. B. \& Eberly, J. (1995), Investment and Q with Fixed Costs: An Empirical Analysis, mimeo, University of Pennsylvania.

[3] Barnett, S. A. \& Sakellaris, P. (1998), 'Non-linear response of Firm Investment to Q: Testing a model of convex and non-convex adjustment costs, Journal of Monetary Economics 42, 67-92.

[4] Bertola, G. \& Caballero, R. J. (1994), 'Irreversibility and aggregate investment', Review of Economic Studies 61, 223-246

[5] Caballero, R. J., Engel, E. M. \& Haltiwanger, J. C. (1995), Plant level adjustment and aggregate dynamics, Working Paper No. 95-09 Dept. of Economics, University of Maryland.

[6] Caballero, R. J. \& Leahy, J. V. (1996), Fixed costs: The demise of marginal Q, NBER Working Paper No. 5508.

[7] Chirinko, Robert S. (1993), 'Business fixed investment spending: Modelling strategies, Empirical Results and Policy Implications, Journal of Economic Literature 31, 1875-1911. 
[8] Cooper, R., Haltiwanger, J. C. \& Power, L. (1995), Machine replacement and the business cycle: Lumps and bumps, mimeo, University of Maryland.

[9] Devereux, M. \& Schiantarelli, F. (1989), Investment, financial factors, and cash flow: Evidence from U.K. panel data, in R. G. Hubbard, ed., 'Asymmetric Information, Corporate Finance, and Investment', The University of Chicago Press, Chicago, pp. 279-306.

[10] Doms, M. \& Dunne, T. (1994), Capital adjustment patterns in manufacturing plants, mimeo, University of Oklahoma.

[11] Fazzari, S. M., Hubbard, R. G. \& Petersen, B. C. (1988), 'Financing constraints and corporate investment', Brookings Papers on Economic Activity 1, 141-195.

[12] Gertler, M. \& Gilchrist, S. (1994), 'Monetary policy, business cycles and the behavior of small manufacturing firms', Quarterly Journal of Economics 109, 309340.

[13] Gilchrist, S. \& Himmelberg, C. P. (1995), 'Evidence on the role of cash flow for investment', Journal of Monetary Economics 36, 541-572.

[14] Goolsbee, A. \& Gross, D. (1997), Estimating Adjustment Costs with Data on Heterogeneous Capital Goods, mimeo, University of Chicago. 
[15] Greenwald, B. C., Stiglitz, J. E. \& Weiss, A. (1984), 'Informational imperfections in the capital market and macroeconomic fluctuations', American Economic Review 74, 194-200.

[16] Gross, D. (1994), The investment and financing decisions of liquidity constrained firms, mimeo, Massachusetts Institute of Technology.

[17] Hayashi, F. (1982), 'Tobin's marginal Q and average Q: A neoclassical interpretation', Econometrica 50, 215-224.

[18] Hoshi, T., Kashyap, A. \& Scharfstein, D. (1991), 'Corporate structure, liquidity, and investment: Evidence from Japanese industrial groups', Quarterly Journal of Economics 106, 33-60.

[19] Hubbard, R. G. (1998), Capital market imperfections and investment, Journal of Economic Literature 36, 193-225.

[20] Kaplan, S. N. \& Zingales, L. (1997), 'Do investment-cash flow sensitivities provide useful measures of financial constraints?', Quarterly Journal of Economics 112, 169-216.

[21] Myers, S. C. \& Majluf, N. S. (1984), 'Corporate financing and investment decisions when firms have information that investors do not have', Journal of Financial Economics 13, 187-221. 
[22] Pratap, S. \& Réndon, S. (1998), Firm investment under imperfect capital markets: A structural estimation, Discussion Paper No. 9808, Centro de Investigación Económia, ITAM.

[23] Schaller, H. (1981), 'A Re-examination of the Q theory of investment using firm level data, Journal of Applied Econometrics 5, 309-325.

[24] Schaller, H. (1993), 'Asymmetric information, liquidity constraints, and Canadian investment', Canadian Journal of Economics 26, 552-574.

[25] Schiantarelli, F. \& Sembenelli, A. (1995), Form of ownership and constraints: Panel data evidence from leverage and investment equations, Working Paper No. 286, Dept. of Economics, Boston College. 
Figure 1: Policy Rules with Fixed Costs of Adjustment

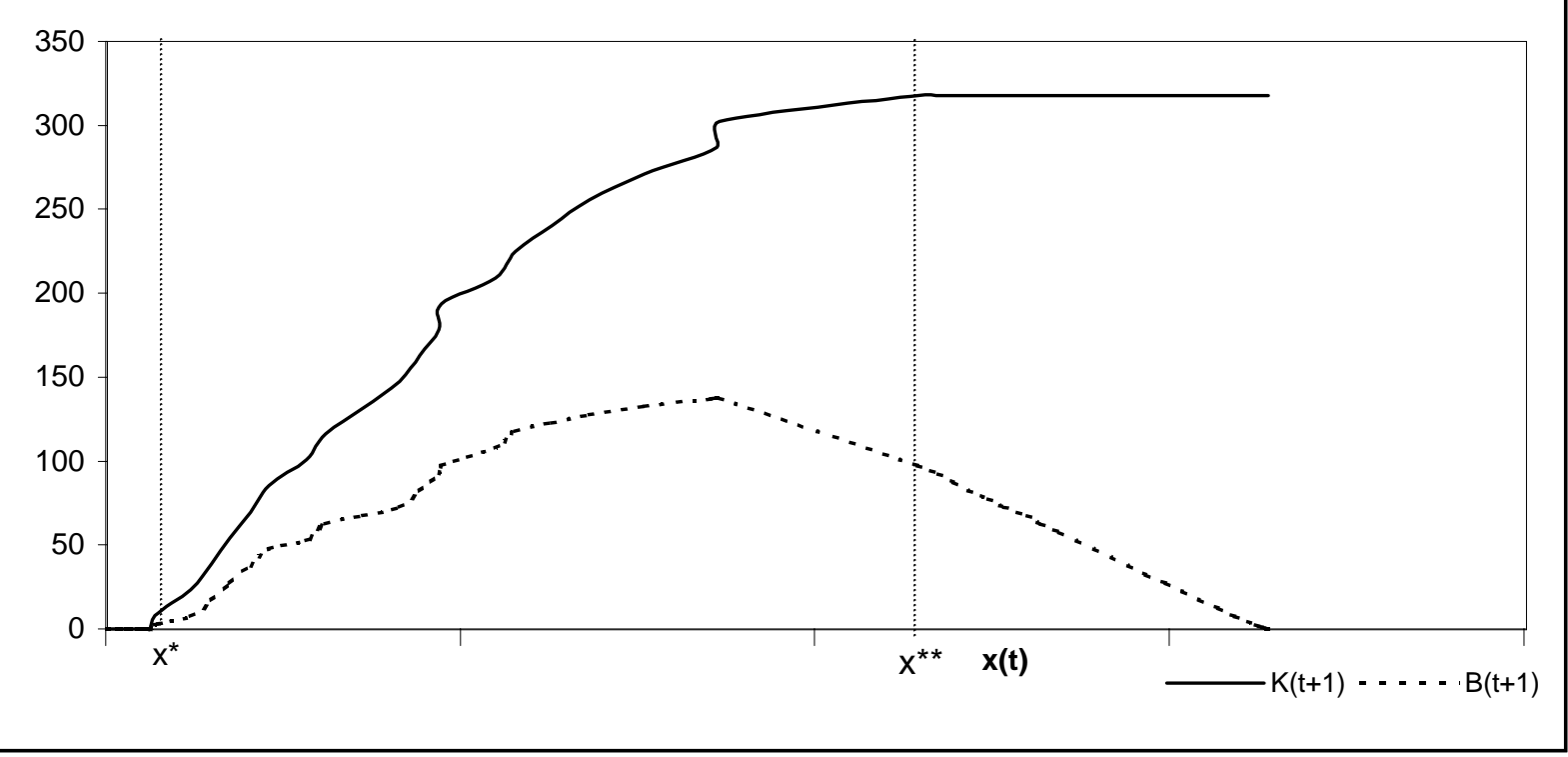




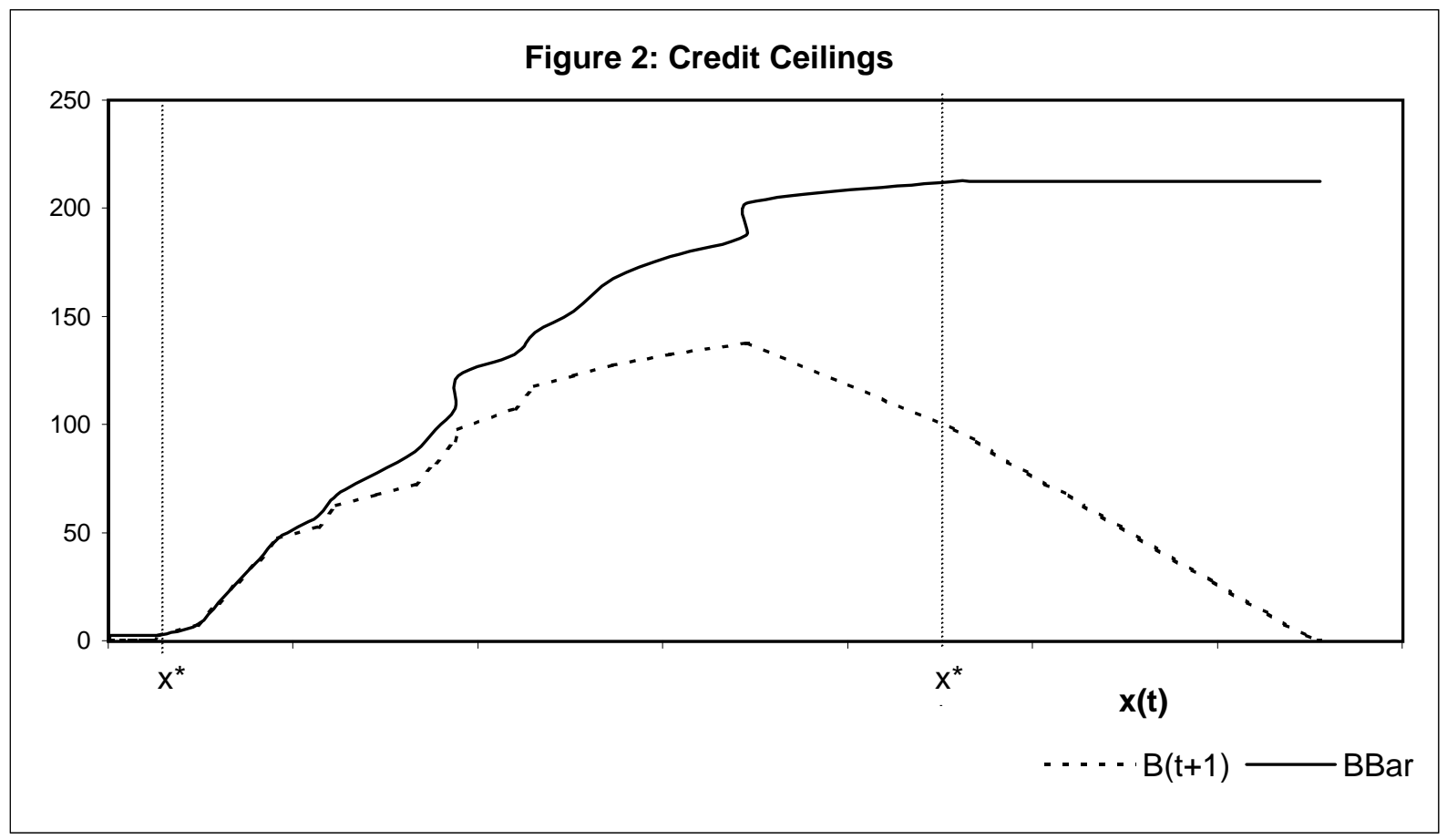


Figure 3: Slope of The Value Function

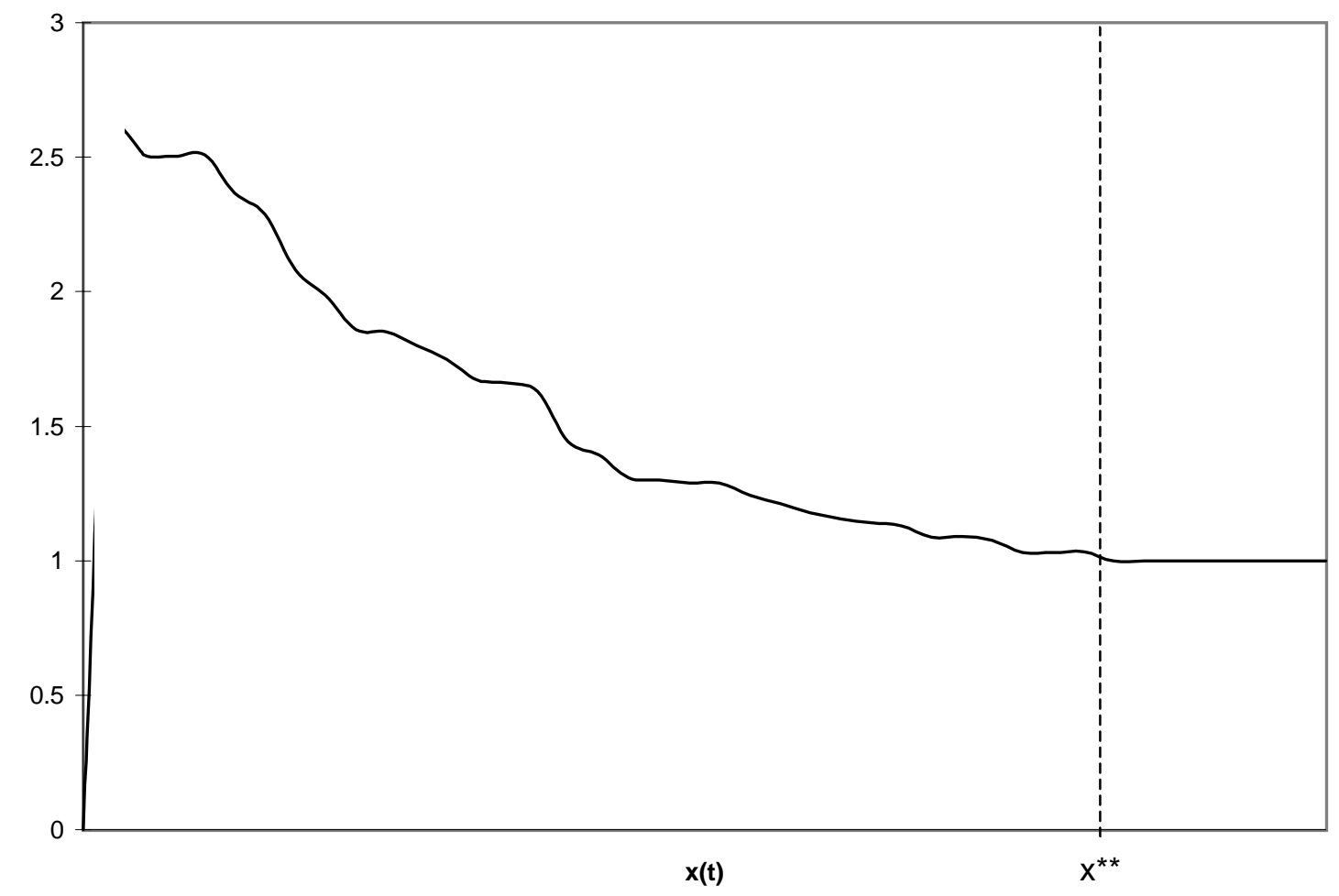



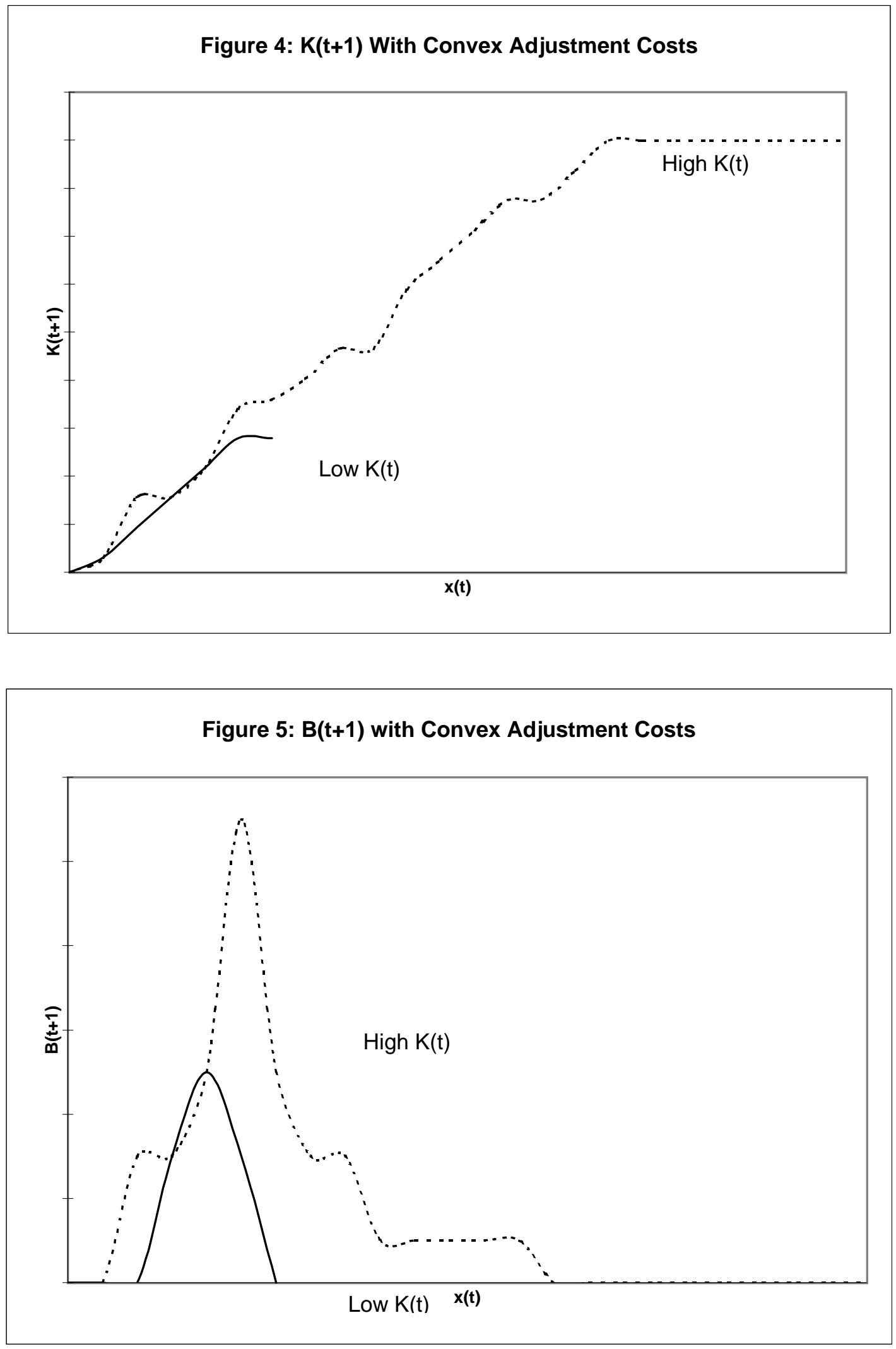